\title{
El joven Garma: de Berlín y Madrid a la organización del psicoanálisis argentino
}

\section{Presentación}

Garma es un gran desconocido en Bilbao, su ciudad natal y de residencia durante su infancia, como lo es en el País Vasco y también en España. Una figura de renombre mundial en el movimiento psicoanalítico latinoamericano, símbolo de una época y una dinámica de creación cultural con una inmensa tarea por él iniciada, con el pretexto de acercar nuevamente su fecunda simiente a esta tierra de la que tuvo que exiliarse en sus más trágicos momentos.

Decía José Bergamín que «enamorarse de la historia es algo peregrino... La historia no se repite según el decir popular» ${ }^{2}$. Lo que sí se repiten son las personas, éstas saben sucederse y saben lo que sucede y lo que ha sucedido aunque nada les haya pasado. (Kierkeegard decía que el que no sabe repetir es un esteta). La historia es como las personas, sucede. «La historia no nos quita el tiempo, nos lo da», también lo dijo Bergamín. Recordar la obra y vida de este pionero, reconocerle su condición de fundador del psicoanálisis en lengua castellana y acercar el conocimiento de este ilustre a la sociedad es también el homenaje a un pionero de altura como Ángel Garma, bilbaíno, de quien en el pasado año 2004 se hubiera celebrado el centenario de su nacimiento.

La psiquiatría y el psicoanálisis tienen características singulares según la actividad y actitudes de los psiquiatras y psicoanalistas, y también según la cultura social donde se inscriben su teoría y su práctica. Describir aspectos importantes de una persona, notoria por la trascendencia de su obra, requiere indagar y evocar acontecimientos relacionados con muchas otras personalidades e instituciones con quienes compartió espacios y tiempos, bélicos muchos de ellos, pues recordemos que las dos guerras mundiales, una guerra civil española y diversos golpes militares en Argentina torturaron su existencia. Son indispensables las revisiones históricas, pues, a través de ellas podemos valorar mejor la obra de los pioneros en cualquier esfera de la vida. También en el psicoanálisis.

La historia intelectual, preocupada de sensibilidades, creencias, valores y acontecimientos desarrollados por el imaginario social, nos aporta multitud de imágenes y discursos, algunos de los cuales es posible rescatar, permitiendo una aproximación a ese universo del psicoanálisis, o mejor al psicoanálisis argentino y latinoamericano. $\mathrm{O}$ al universo de este bilbaíno cuya vida y obra, que tanta tras-

1 José Bergamín. «Larra, peregrino en su patria», Hora de España, 1937, n. ${ }^{\circ} 11$. 
cendencia tuvo en aquellas lejanas tierras durante varias décadas del pasado siglo, en momentos de afán modernizador de la cultura, siendo un gran desconocido en su tierra natal.

\section{Infancia}

Ángel Juan Garma y Zubizarreta, nació un 24 de junio de 1904 en Bilbao, en la Gran Vía bilbaína, zona de clase media y ambiente refinado en aquellos inicios de siglo, al lado de los recién fundados Banco Vizcaya, Banco Aurora y el Crédito de la Unión Minera que nacían con pujante agresividad financiera. Estrenó su familia una amplia vivienda, de unos $250 \mathrm{~m}^{2}$, contigua a la antigua ubicación del Noticiario de Bilbao, y a un centenar de metros del edificio de la Diputación Foral, en un magnífico emplazamiento del ensanche bilbaíno. Su padre, Ángel Manuel de la Garma y Setién, comerciante, que nació el 15 de octubre de 1862 en Guriezo, pequeña población de Cantabria que ya entonces contaba con cuatro ferrerías, precedentes de las fábricas siderometalúrgicas. Su madre, Cirila Zubizarreta, vino al mundo el 9 de junio de 1879 en Bilbao. Ángel Manuel y Cirila tuvieron tres hijos: Ángel, José María y Maria Teresa.

El abuelo materno, Cirilo de Zubizarreta, nació en Baranbio (Araba) el 9 de julio de 1847, con 17 años de edad pasó a vivir a Bilbao, y fue pintor de profesión. Su abuela materna, Marcelina de Aguirre y Villanueva, era natural de Gordexola (Bizkaia). Ángel Garma comentaba en ocasiones que era de familia con sentimientos de ser «vascos por los cuatro costados». También ateos y anticlericales, aunque fuera bautizado en la parroquia de San Vicente de Abando el 14 de julio ${ }^{2}$, un espléndido templo del siglo XVI, de época renacentista con estructuras arquitectónicas del llamado «gótico vasco».

Su padre, que se había marchado a Buenos Aires, donde puso un próspero negocio de porcelanas con su hermano, conoció en uno de sus viajes a Bilbao a la que iba a ser su mujer, Cirila, casándose poco después. El padre habitualmente estaba ausente de la casa familiar. Cuando Ángel tenía cuatro años su madre también emigró a Buenos Aires, llevando a la menor de los tres hijos, permaneciendo en Bilbao junto a su hermano José María, donde vivió su infancia al cuidado de sus abuelos maternos y las niñeras.

Ángel Garma quedó huérfano de modo temprano, al aparecer muerto su padre en el almacén del negocio que poseía en Buenos Aires a los pocos meses de

2 Libro número 56 de bautizados de la parroquia de San Vicente Mártir de Abando, pp. 12-13. Actualmente en el Archivo Histórico Diocesano de Derio. 
establecerse en aquella ciudad con la madre. Ángel quedó sumergido en la simplicidad con que se ven las cosas a los cuatro años. O como decía Betty Goode «sucedió un drama: el padre en Buenos Aires, y dicen que se suicidó de dos tiros...». Yo lo dudo, pienso que fue un drama familiar porque el hermano del marido, a los siete meses del suceso se casó con la madre de Ángel. Es el estudio de Hamlet. Por ello, lo que iba a ser una breve estancia con los abuelos se prolongó durante toda su infancia y adolescencia.

Recordaba con mucho dolor, que su abuela le contaba cuentos muy feos que le atemorizaban. Contaba uno sobre «una fuente donde bebían agua las personas $\mathrm{y}$, al hacerlo, penetraban serpientes en el cuerpo de quienes bebían y enfermaban». Quizá de allá partiese su interés por ahondar en el lenguaje gráfico y, como no, su fascinación por investigar sobre los sueños. No dio, al menos por sus comentarios familiares, la idea de una infancia feliz. Después, aun en plena infancia, se trasladaron a vivir a la Gran Vía del Casco Viejo de Bilbao, la actual calle Correo, donde se crió con la abuela en un ambiente acomodado económicamente.

Pocos meses después del fallecimiento del padre, su madre contrajo de nuevo matrimonio con su cuñado, Salvador Garma, con quien tuvo las que serían sus «dos medio hermanas», Inés y María Teresa, y otro hermanastro, Salvador. En pocos meses se trasladaron a Viena, residiendo varios años en la María Teressen Strasse, muy cerca del domicilio de Sigmund Freud, cuya escuela psicoanalítica acogería años más tarde a Garma. La ausencia del padre y de la madre, sustituidos por los abuelos, fue difícil de explicar creyendo que si cerraba los ojos le escucharían desde donde estuvieran. Una historia edípico hamletiana que el mismo Garma, con humor, mitificaba y relacionaba con su pasión por la investigación psicoanalítica, pues parece estar en el origen de su vocación. Pudo ser la duda sobre aquella pérdida brutal lo que le impulsó a interesarse por los misterios de la vida de los demás a través de la medicina primero, y el psicoanálisis después.

Vivía en aquel Bilbao, con sus casi cien mil habitantes tras las anexiones de Begoña y Abando, la cuarta parte de la provincia, en una ciudad que había aumentado su población en el siglo XIX, a pesar de las agitaciones y luchas políticas. La naciente industria siderometalúrgica y los astilleros exigían una mano de obra que fue proporcionada por oleadas de emigrantes, que provenían de la propia provincia de Vizcaya y de las provincias limítrofes: Santander, Burgos, Álava y, en menor medida, de otras provincias cercanas aunque no fueran limítrofes, e, incluso, desde Galicia. Fueron años de crisis de subsistencia, con numerosos conflictos laborales, protestas espontáneas por los alquileres de las viviendas y los precios de productos básicos, huelgas en la cercana minería y con grandes tensiones entre socialistas y republicanos, todas ellas muy presentes. Las duras condiciones de trabajo dan lugar al nacimiento y desarrollo de un potente socialismo que adquiere fuerza y prestigio 
en distintas huelgas que conmueven a la población y desembocan en enfrentamientos con el ejército y la Guardia Civil. Con un PSOE que iba obteniendo sus primeros diputados, que se implantaba también en los ambientes universitarios y profesionales, transformándose en un partido de masas, alcanzando gran implantación en Asturias, Vizcaya y Madrid, zonas de importantes luchas obreras junto a Barcelona, plaza fuerte del anarquismo. Una primera década del siglo de gran virulencia y conflictividad social que definió un período del obrerismo vizcaíno denominado de «guerra sin cuartel» que pone de manifiesto las grandes transformaciones sociales en curso en esos años que llevarían a la gran huelga de 1910, centrada por los trabajadores, mineros, principalmente, en la reducción de la jornada laboral pero que sería tachada por los empresarios de complot revolucionario.

Un Bilbao pujante en una España decaída y desprestigiada como la del 98. Ciudad industrial y mercantil con gran empuje vital, primera ciudad estatal en utilizar el hierro y el cemento armado en la construcción de sus grandes edificios, de vocación europeísta por influjo inglés (fútbol, clubes, empresarios inversores, etc.). La emigración interior y nuevos desarrollos debido a la industrialización a través de la siderurgia, los astilleros y la minería produjeron un fuerte crecimiento de Bilbao y los núcleos industriales próximos favorecido por la construcción de toda una red ferroviaria y la canalización de la ría y el nuevo puerto exterior. En aquel Bilbao pujante, a Ángel Garma le hacían aprender a tocar el violín, en casa y en la escuela, lo cual le disgustaba sobremanera y, cuando tenía que estudiar las partituras, colocaba un libro de lectura encima de ellas disimulando ante las miradas controladoras. Criado entre libros haciendo amigos invisibles, no olvidaba a sus visibles compañeros de correrías. Cuando acudió a Bilbao setenta años más tarde, en 1989, comentaba: «... recuerdo que en mi infancia había unas vagonetas de mineral que cruzaban la ría... muy cerca del puente de San Antón».

No vio al nuevo «padre» ni a la madre hasta los nueve años. «Él tiene como recuerdo a la madre alejándose en un coche de caballos con su nuevo marido. Es un recuerdo muy traumático que le quedó. A los nueve años volvieron, le recogieron junto a su hermano menor y se instalaron en Madrid. Así tuvo su segunda pérdida, porque perdió a la abuela», decía Betty Garma. En Madrid se escolarizó en un colegio de los Jesuitas realizando su bachiller con excelente aprovechamiento y haciendo, poco a poco, nuevas amistades. Posteriormente, aquel colegio fue quemado durante la II República.

\section{La residencia de estudiantes}

A los diecisiete años inició sus estudios de Medicina en la Universidad Central (actual Universidad Complutense) de Madrid y ya desde el comienzo 
pensó en dedicarse a la psiquiatría. Tuvo insignes profesores como Santiago Ramón y Cajal (1852-1934), quien en unos años de ingente investigación sobre la teoría neuronal, en 1925 centró sus estudios en las neuroglias y demostró fotográficamente los fenómenos de regeneración del nervio, reforzando los descubrimientos de Pío del Río Ortega. Y fue durante cuatro años alumno interno en la cátedra de Fisiología de Gregorio Marañón, muy interesado éste por el psicoanálisis, que en 1923 desarrolló una precursora teoría cognitiva de las emociones. También estuvo con Marañón, como interno en el Servicio de Patología Médica del Hospital General de Madrid en el curso 1926-1927. En ese año publicó diversos trabajos, solo o con Marañón, en la revista Medicina Ibera ${ }^{3}$ y también en el libro de su maestro Trabajos del Servicio de Patología Médica ${ }^{4}$. Marañón, Cajal y otros profesores, por algún motivo, adoraban a Garma que era un alumno muy apreciado en los diferentes cursos. Allí se graduó en 1927. «Estudié Medicina en una época muy interesante en España, la época anterior a la República. Esos inicios de los años veinte fue un tiempo de gran efervescencia política y social, e importante desarrollo en los ambientes culturales y científicos». Con Marañón mantuvo su relación epistolar durante tres décadas. En 1956, estando Gregorio Marañón elaborando el libro El Greco y Toledo, Garma le comentó: «He revisado todas mis revistas psicoanalíticas, que son prácticamente todas, para encontrar algo sobre El Greco. No hay ningún artículo referente a él. Sólo en un libro, de alguien que no pertenece al ambiente propiamente psicoanalítico, he encontrado una interpretación psicoanalítica sobre $E l$ entierro del conde Orgaz». Marañón lo agradecería en el libro: «debo esta referencia a mi amigo y antiguo discípulo, el conocido y culto psicoanalista argentino, Ángel Garma».

Trabajó con el doctor Miguel Sacristán en el servicio de mujeres del Hospital Psiquiátrico de Ciempozuelos, viviendo junto a su hermano menor, José María, en la Residencia de Estudiantes, buque insignia de la Institución Libre de Enseñanza, fundada por Francisco Giner de los Ríos en cuyo lugar y ambiente estuvieron presentes muchas de las personalidades de las nuevas tendencias y movimientos culturales de Europa, muchos de los cuales, pocos años después, tendrían que marchar al exilio o se verían condenados al silencio del exilio interior. Allí escuchó

\footnotetext{
3 Marañón, Jimena y Garma, «Los reflejos de proyección visceral en la patología tiroidea», Medicina Ibera, 1927, Año XI, n. ${ }^{\circ}$ 14, pp. 205-206. Garma, «Consideraciones sobre un caso de prediabetes», Medicina Ibera, 1927.

4 En Trabajos del Servicio de Patología Médica del Hospital General de Madrid, 1926-1927, figuran las siguientes comunicaciones del Dr. Garma: «Un caso de febrícula por tiñitis postifoidea» (Con Marañón), p. 20; «Reacciones de proyección visceral del tiroides» (Con Jimena), p. 39; «Un caso de prurito prediabético», p. 53; «Un nuevo caso de edema angloneurótico con localización visceral», p. 108; «Lesión parahipofisaria sin síntomas glandulares», p. 113; «Sobre la adiposidad dolorosa», p. 135.
} 
conferencias impartidas por grandes ilustres como Albert Einstein ${ }^{5}$, Paul Valéry ${ }^{6}$, Jhon Keynes, Pierre Janet, Marie Curie o el arquitecto Le Corbusier, el que dijera que lo que más le había gustado de España era la frase de «dar una estocada». García Lorca explicaría ese comentario de Le Corbusier como expresión de una intención profunda de ir al tema y el ansia de dominarlo rápidamente, sin detenerse en lo accesorio y decorativo.

También allí coincidió con Federico García Lorca, Salvador Dalí, Luis Buñuel, Severo Ochoa, García Valdecasas, Mariano Bustamante, Pepin Bello Lasierra, Pedro Garfias, José M. ${ }^{a}$ Hinojosa y otros jóvenes tan cargados de iniciativas, nada famosos aún en esa época, con quienes se generó una importante complicidad intelectual, que evocan la eclosión de nuevas formas y desarrollos del arte y la cultura de aquellos años. Y que acabaron jugando un papel preeminente en un período de gran riqueza de la intelectualidad en todos los ámbitos culturales. Entre los grandes atractivos de La Residencia estaban las tertulias nocturnas, a las que acudía la «inteligentzia» residente en Madrid. El Ateneo, el Café Gijón o la Residencia de Estudiantes fueron lugares de encuentro de maestros consagrados y futuros artistas de la Generación del 27. «Prácticamente me encontraba todos los días con ellos, comía y conversaba con ellos. Esa convivencia me dio ideas muy interesantes que luego me sirvieron mucho y que formaron mi espíritu». A García Lorca, a quien conoció siendo éste universitario en Madrid, y de quien fue gran amigo aunque fuera seis años mayor que él, le recordaba como «un ser encantador, simpático, brillante y algo neurótico, que podía ser muy cruel con las personas que le querían» $\mathrm{y}$, a menudo, también recitando poemas con su matizada voz durante sus paseos o tocando el piano Pleyel de aquel salón sobrio de la Residencia, lugar de escasos adornos y con más bien escaso mobiliario, e incluso preparando alguna conferencia. Pero Lorca amó mucho y sufrió por amor. Garma acudió en algunas ocasiones a esquiar a Sierra Nevada, coincidiendo con Federico García Lorca en su ciudad, Granada.

A Salvador Dalí le definió como «un autista» ${ }^{7}$, aludiendo a su comportamiento retraído y apocado, de enorme timidez que disimulaba con excentricidades, cierta insolencia y organizando escándalos académicos ${ }^{8}$ que llegaban a situa-

\footnotetext{
5 Einstein estuvo en 1923, invitado por varios grupos de científicos españoles, e, impartió conferencias en Barcelona, Zaragoza y Madrid, ciudades donde se cursaban estudios de Física.

6 Recordaba que habló de Baudelaire y el futuro.

7 Entrevista en Cambio 16, 1989.

8 Salvador Dalí fue expulsado en dos ocasiones de la Escuela de Bellas Artes de San Fernando; la segunda y definitiva en octubre de 1926 por declarar incompetente al tribunal examinador siendo llamado meses después al Servicio Militar de «cuota» durante nueve meses. Ello significó su alejamiento definitivo de Madrid y el abandono de la Residencia de Estudiantes, yendo a trabajar incansablemente a su taller de Figueres y exponiendo en Barcelona, Madrid y París.
} 
ciones comprometedoras para el grupo, que no logró moderarle y por ello le expulsaron del mismo. Garma decía que la supuesta locura era un simple recurso defensivo para llamar la atención de ese que repetía «yo soy residente de estudiantes» en alusión a la Residencia. Curiosamente quizá fuera Dalí quien le diera el impulso inicial para acercarse al psicoanálisis cuando éste leía en voz alta o comentaba fragmentos de La interpretación de los sueños de Freud, obra que le apasionó y sobre la cual siguió investigando.

Y estuvo con Severo Ochoa que dirigía un bien equipado laboratorio de Fisiología en los sótanos de la Residencia y con el cual aprendió mucho, como se lo recordaría cuando en los años cincuenta volvieron a verse en los Estados Unidos en sus exilios voluntarios. Coincidieron también en el laboratorio con García Valdecasas y Grande Cobian, todos ellos formados bajo el estímulo de Juan Negrín. También, años más tarde, estando en Buenos Aires añoró aquel grupo, hablaba de ellos con frecuencia, comentaba opiniones y correrías de aquella época. O recordaba algunas confidencias, siempre con absoluto respeto.

A finales de mayo de 1926 fue convocada una reunión de la Asociación de Antiguos Residentes a la cual acudió Garma, decidiendo la utilización de la revista Residencia como órgano de comunicación. En los veranos de 1926 y 1927 hizo el Servicio Militar en la Brigada Obrera y Topográfica. El primer verano como estudiante y el segundo ya como médico, teniendo calificación final de sobresaliente.

En esos años, José Ortega y Gasset era catedrático de Metafísica de la Universidad de Madrid, desde 1916 hasta 1936, y vinculado a la Institución Libre de Enseñanza, muy crítico frente a la España tradicional de la «Restauración», heredero del ideal europeizante de la generación del 98, fue el introductor de las corrientes filosóficas alemanas del primer cuarto de siglo en los países de habla castellana y su devastadora crítica al positivismo tuvo gran acogida entre las nuevas generaciones de filósofos. Fue el responsable de haberse editado en 1922 la primera y excelente traducción al castellano de las, entonces, Obras completas de Freud, realizada por Luis López Ballesteros, con prólogo del propio Ortega, pues tras leer éste a Freud en alemán quedó tan entusiasmado que recomendó a su amigo Ruiz Castillo, propietario de la editorial Biblioteca Nueva, su publicación ya que los trabajos de Freud eran muy apreciados y su lectura era creciente en Europa. Esta cuestión no tuvo parangón en otras lenguas pues hasta ese momento sólo se conocía la obra de Sigmund Freud en alemán, lo cual puede orientar sobre la atención que se daba a los fenómenos culturales en los círculos intelectuales. Además, la Revista de Occidente, dirigida por Ortega, publicó numerosos artículos sobre psicoanálisis entre los años 1923 y 1925 y con trabajos sobre la teoría psicosocial del llamado «hombre-masa», o con reseñas de trabajos freudianos rea- 
lizadas por García Morente, Sacristán o Rodríguez Lafora. En los siguientes años, Freud prácticamente desapareció de sus páginas pasando a ser Jung un colaborador habitual, siguiendo los vaivenes de las corrientes dominantes en el psicoanálisis europeo.

Ortega y Gasset que había contribuido a la caída de Alfonso XIII, una vez instaurada la II República, en su discurso de 6 de diciembre de $1931^{9}$ le daría la espalda. En su Rectificación de la República propone una República sin pluralismo político ni partidos políticos, contrario a la reforma agraria, los estatutos de autonomía y la separación Iglesia-Estado, en suma, una gran parte de los logros sociales y democráticos republicanos.

\section{Los años de Berlín}

Posteriormente, tras consejo de Sacristán, su profesor de psiquiatría, gran conocedor de la obra de Kraepelin y difusor del pensamiento freudiano, con quien discutía frecuentemente los historiales clínicos y del cual Garma dijo que tenía un diván en la consulta para tratar «psicoanalíticamente» a algunos pacientes, se orientó hacia la neurología y la psiquiatría, yendo a Alemania a especializarse en 1927. Se marchó con una ayuda económica de la Junta de Ampliación de Estudios (JAE) de la Residencia de Estudiantes, al igual que otros muchos de la llamada generación de 1914-27, artífices todos ellos de la renovación cultural española lograrían poner en marcha el pensamiento racional. Al año siguiente sintió no poder acudir a la Reunión de la AEN, la Asociación Española de Neuropsiquiatría, que se celebró en Bilbao y además intervinieron sus profesores Sanchís Banús y Sacristán ${ }^{10}$. Obtuvo el diploma de Psiquiatra en la Universidad de Tübingen en 1929, tras trabajar un año con el profesor Gaupp. Solía comentar que fue una experiencia decepcionante pues la psiquiatría clásica no satisfacía sus deseos de investigar en el campo de las enfermedades mentales, pero descubrió la existencia del psicoanálisis. A mediados de la década de los años veinte, el psicoanálisis como disciplina se hallaba en auge, Alemania era el centro más importante de las investigaciones psicoanalíticas y él estaba en ese país.

Más tarde, Garma desarrolló estudios de perfeccionamiento médico y psiquiátrico en Berlín para lo cual volvió a solicitar otra ayuda a la JAE, acordando desde esta institución «concederle la consideración de pensionista para estudiar

9 Publicado en La Vanguardia, 12-8-04

10 Sanchís Banús y Sacristán, explícitos freudianos entre los psiquiatras españoles, presentaron en la III Reunión de la AEN una ponencia sobre «Diagnóstico diferencial entre esquizofrenia y psicosis maniacodepresiva». 
psiquiatría y psicoanálisis en Alemania» en marzo de 1929. Estudios que realizó en la clínica universitaria de Von Hoeffer donde conoció a la joven profesora de la clínica y psicoanalista Micaela Fabián, quien le sugirió una formación psicoanalítica. Pocos días después, introducido por la doctora Fabián, acudió al Instituto Psicoanalítico de esa ciudad, presentándose a su director, Max Eitingon, quien aceptó con mucho gusto la solicitud de Garma. Max Eitingon, con quien posteriormente desde la Argentina Ángel Garma mantuvo una intensa correspondencia epistolar, fue presidente de la API entre 1927 y 1932, estableciendo las normas dictadas para la asociación internacional. A pesar de no ser buen orador (era tartamudo) y haber escrito muy poco, tuvo gran influjo en la marcha internacional del psicoanálisis. Desde 1913 miembro del Comité secret, grupo formado por Sigmund Freud, Ernest Jones, Sandor Ferenczi, Karl Abraham, Otto Rank, Hanns Sachs y él mismo, dirigió durante dos décadas los destinos de asociaciones y miembros centrados en la tareas de institucionalizar y orientar el inconsciente, al objeto de contrarrestar los intentos de disidencia o de copar la dirección de la Asociación Internacional de Psicoanálisis por psicoanalistas «desviacionistas», presidiendo la Internacional o conduciendo sus publicaciones. Los siete, desde cuatro ciudades (Berlín, Viena, Budapest y Londres), dirigieron durante dos décadas los destinos de asociaciones y miembros, centrados en la tarea de institucionalizar y orientar el inconsciente social y de sus pacientes.

En Berlín conoció a muchos maestros, coincidiendo con grandes nombres de la historia del psicoanálisis y de la psiquiatría, algunos de los cuales fueron compañeros de seminarios: Franz Alexander, Berta Bornstein, Therese Benedeck, Frieda Fromm-Riechman, Edith Jacobson, Wilhelm Reich, Siegfriend Bernfeld, René Spitz, Carl Gustav Jung, George Groddeck, Erich Fromm, Alfred Adler, Hans Sachs y otros. Agradeció la aportación humana y científica de sus profesores y supervisores, Karen Horney ${ }^{11}$, Otto Fenichel y Jenö Harnik, grandes ilustres del psicoanálisis internacional, y también estableció una gran amistad con su «hermana de diván», Paula Heimann. Asimismo, conoció en Berlín a Anna Freud y después a Lou Andreas-Salomé quien parecía haber dominado la mayor parte de las fragilidades humanas, y sobre quien recordaba: «esa mujer me infundía temor, temía ser absorbido por ella y no poder zafarme. Tenía unos pechos enormes y una gran atracción sensual». Berlín era en esos años el corazón del mundo psicoanalítico internacional. Allí también hicieron su formación Adelheid Koch, quien fundara el movimiento psicoanalítico brasileño en Sao Paulo y a Werner Kemper que

11 Es muy posible que de Karen Horney tomara la idea, que luego transmitió a Arnaldo Rascovsky quien la desarrollaría; que también el hombre tiene envidia a la mujer, especialmente cuando está embarazada. «El hombre es impotente porque fantasea en la entrada de la vagina, la presencia del pene del padre que le prohíbe entrar, como el ángel con la espada flamígera impidió a la pareja primitiva volver a entrar en el paraíso». 
participó del desarrollo del psicoanálisis en Río de Janeiro, siendo los tres, buenos colaboradores en el desarrollo del psicoanálisis latinoamericano.

Comenzó a analizarse con Theodor Reik, psicólogo laico y analista profano, discípulo directo de Freud, por quien fue defendido en Viena en un juicio por ejercicio de la medicina como curandero debido a su fobia a los médicos. Freud en su defensa escribió «Psicoanálisis no-médico» y, tras ese episodio, Reik emigró instalándose en Berlín donde el ejercicio era libre no precisando ser médico, pasando a ser docente del Instituto Psicoanalítico de esa ciudad. Garma invirtió su herencia familiar en estudiar psicoanálisis y en psicoanalizarse durante tres años «... Empecé a psicoanalizarme y me pareció un proceso maravilloso... Para mí el encuentro con el psicoanálisis fue una maravilla, tuve la sensación de que era lo que había estado buscando toda mi vida sin conocerlo. Así como con la psiquiatría había tenido una cierta desilusión que no percibía conscientemente, pero que sentía dentro de mí, con el psicoanálisis fue una sensación de maravilla absoluta». Obtuvo en 1931 su diploma de estudios de grado como psicoanalista «aquello tuve la impresión de haber estado toda la vida buscándolo» siendo admitido como miembro de la Asociación Psicoanalítica Alemana tras la presentación de su trabajo La realidad y el ello en la esquizofrenia (Die Realität und das Es in der Schizofrenie) publicado en Internationale Zeitschrift für Psychoanalyse, donde disentía con algunas posiciones clásicas de Freud sobre la estructura de la neurosis y la psicosis incidiendo en que las tesis de aquél no eran válidas, pues los fenómenos en las neurosis y las psicosis transcurrían al revés de lo señalado en la teoría general de Freud. Según Garma, «la estructura mental del neurótico sería similar a la del psicótico, con un yo sometido de modo masoquista por un rígido super-yo que contiene los impulsos del ello». A través de la esquizofrenia, una caricatura de comportamientos menos patológicos, aclara el significado de frecuentes síntomas neuróticos o de fenómenos psíquicos normales. Garma polemizó con Freud y además se lo envió por correo. Sigmund Freud le enviaría una postal, en respuesta al envío de sus primeros escritos para que el creador del psicoanálisis los leyera. En ella le decía: «Le agradezco mucho el envío de sus valiosos trabajos... (puedo leer fácilmente el español)... mis mejores deseos para su éxito en su patria».

Ya antes, publicó en 1930, en Berlín Un gesto obsceno de Santa Teresa ${ }^{12}$ y desde Berlín, había enviado dos trabajos a Archivos de Neurología de Madrid donde reflejaba el importante conocimiento de las ideas freudianas: La transfe-

12 Título original Eine obszone Gebarde der heiligen Teresa, basándose en una conferencia pronunciada en la Asociación Psicoanalítica Alemana el 6 de mayo de 1930 y editado en ese mismo año en el Psychoanalitische Bauegung, tomo II. 
rencia afectiva en el psicoanálisis y Cómo se estudia el psicoanálisis fueron esos estudios. Este artículo que reproducirá en su monografía de 1936 se acompañaría de un prólogo de Theodor Reik, su analista didáctico: «Yo ya sé que los conocimientos teóricos del psicoanálisis son bastante conocidos por los psiquiatras y psicólogos de su hermoso país. Pero sé también que pocos han comprendido que solamente aquel que se somete a un psicoanálisis profundo puede adquirir un conocimiento verdadero de este método psicológico... Era tan grande el interés que usted tenía hacia los aspectos psicológicos y psicoterapéuticos de la doctrina de Freud, que no retrocedió ante las molestias y sacrificios que trae consigo un estudio del psicoanálisis en el extranjero. A su vuelta, no se contentó usted con aprovechar en la práctica médica la ventaja que proporciona la experiencia de su propio análisis. Ha sentido usted la necesidad de hacer profundizar el conocimiento del psicoanálisis en la patria querida, de destruir confusiones que allí se habían creado, y de demostrar a los colegas las posibilidades del método de la psicología profunda... Yo no dudo que sus esfuerzos nacidos de una rectitud interior y de energía intelectual, le conducirán a usted a la meta deseada. Esté usted confiado y tranquilo. La verdad, finalmente, consigue siempre triunfar...»

Garma se mostró siempre fiel a la doctrina y a la disciplina psicoanalíticas. María Luisa Muñoz, una de sus discípulas piensa que «Garma, consciente de la viciada situación española... insiste en la importancia del análisis didáctico, considerando la formación autodidacta como insuficiente para realizar una práctica psicoanalítica y para llegar a comprender la importancia de los mecanismos inconscientes. Critica la utilización ecléctica que los psiquiatras españoles vienen haciendo del psicoanálisis en su teoría $\mathrm{v}$ en su práctica. Podemos pensar que Garma intentaba desde antes de su llegada a Madrid presentarse como psicoanalista, diferenciando claramente la formación psiquiátrica de la formación psicoanalítica, postura que mantuvo durante todos los años de su estancia en España, y que le creó importantes tensiones con los medios psiquiátricos». Mientras la Psiquiatría describía los síntomas y los agrupaba determinando clasificaciones diagnósticas de enfermedades, el Psicoanálisis era una psicología profunda. El psicoanalista debía vencer sus represiones para conocer el inconsciente de los pacientes, debía psicoanalizarse y para eso no bastaba con la lectura de la obra de Freud, se requería una capacitación más intensa.

Socialmente se vivía un gran esfuerzo de recuperación cultural tras la crisis del 98, sobre todo en los años en torno a la II República. El envío de jóvenes promesas en diferentes ámbitos de las ciencias hacían presagiar buenos augurios. La obra de Cajal en la neurología e histología, la adscripción de la psiquiatría a la corriente alemana, kraepeliniana en aquellos momentos, con importante atención a lo somático, sustituyendo el influjo psicologizante de la psiquiatría francesa, y 
la actitud de algunos psiquiatras jóvenes que optaban por una mejor formación en el extranjero, donde era mayor el desarrollo psicoanalítico, la búsqueda de la excelencia médica positivista y la preocupación por el rigor científico eran muchos elementos favorables para el fomento y desarrollo cultural y científico. La psicología española estaba orientada hacia el conocimiento teórico y las aplicaciones técnicas, sobre todo a la psicotecnia. También en la II República aumentó la difusión de las ideas psicoanalíticas que se plasmaron en eventos dispares: organización de semanas sobre Higiene Mental, celebración de Jornadas Eugénicas, proyecto de Ley sobre el divorcio, etc. Se ha llegado a hacer una correspondencia entre las posturas psiquiátricas que se manifestaban sobre el Psicoanálisis y los posicionamientos ideológicos y políticos. Había quienes siendo muy conservadores como Villaverde, López Ibor y Vallejo Nájera, con matices entre unos y otros, rechazaban las formulaciones freudianas. Pero la aceptación mayoritaria y los mayores entusiasmos coinciden en psiquiatras con idearios de izquierdas: posiciones liberales de izquierda de Rodríguez Lafora o de Sacristán; socialistas como Sanchís Banús o César Juarros; o comunistas como Mira i López. Significativo sería que el acontecer de la guerra civil y con el acceso al poder del franquismo, el único exponente del psicoanálisis -Garma- tuviera que exiliarse. Tras la victoria franquista, los vencidos y de izquierda se exiliaron o emigraron, mientras que los del bando de los vencedores y de derechas ocuparían importantes cargos en las instituciones oficiales, universitarias, científicas, asistenciales y profesionales.

\section{1: vuelta a Madrid}

Garma regresó en 1931 a Madrid, tras haber caído el año anterior la dictadura del general Primo de Rivera y quedar una debilitada monarquía que pronto sería desplazada por la II República. En la capital se integró en el ambiente cultural y científico dominante en los años previos a la guerra civil, años del sueño republicano de quienes creían en una España fuerte coexistiendo con las singularidades de Galicia, Euskadi y Cataluña. Encontró una fuerte oposición para expandir el psicoanálisis por parte de los psiquiatras. Él era el primer psicoanalista español, nacido en Bilbao, miembro de la Asociación Psicoanalítica Internacional (API), aquella asociación que fundara en 1910 el mismo Freud, y que comenzaba a ejercer en España. Fue invitado al XII Congreso de Psicoanálisis de Weisbaden en septiembre de 1932 donde estuvo con la plana mayor del psicoanálisis europeo. Este Congreso fue conocido porque en él se impuso una cuota de tres dólares por mes a todos sus miembros, así como por la polémica entre los grandes líderes (Eitingon, Jones, Freud, Brill) organizada en torno a si Ferenczi -quien debía 
acceder a la presidencia de la Asociación Internacional- leía el trabajo que había preparado. De nuevo, las rivalidades internas por la dirección de la API.

Sin embargo, trabajando en Madrid sintió que la hostilidad de los psiquiatras no le permitía hacer un trabajo adecuado como psicoanalista. «Me encontré en medio de circunstancias desfavorables, tanto científicas como profesionales», decía, pues en pleno dominio de corrientes organicistas, el estamento médico se oponía al psicoanálisis.

Trabajó como psiquiatra en el Tribunal Tutelar de Menores en Madrid escribiendo, como resultado de su experiencia, la obra Psicoanálisis y Criminología. Las tendencias antisociales del psicópata hacían que entrara en conflicto con la sociedad, la cual pretende rehabilitarlo y convertirlo en una persona normal e integrada mediante el castigo. Pero ese castigo pudiera ocasionar mayor odio contra la sociedad generando un círculo vicioso que favorece la reincidencia y provocaba un nuevo castigo. De ahí que propugnara la supervisión del castigo en el tratamiento de los delincuentes, y su sustitución por una psicoterapia efectiva, llegando a conocer los motivos inconscientes de la acción delictiva. Prestigiosos de la medicina y la psiquiatría le reclamaban para dar conferencias y debatir: Marañón, Lafora, Sacristán, Sanchís Banús, sus anteriores maestros y otros muchos, etc. Dio cursos y conferencias sobre psicoanálisis en la Sociedad de Neurología y Psiquiatría, en los Servicios de Psiquiatría de Sanchís Banús y de Sacristán, en la Liga de Higiene Mental y en el servicio hospitalario que dirigía su maestro, Gregorio Marañón. En algo más de cuatro años de estancia en Madrid publicó el libro El psicoanálisis, la neurosis y la sociedad, libro con varios trabajos donde expone las bases del psicoanálisis, la formación y sus aplicaciones sociales y terapéuticas, además de otros 17 artículos con temas tan variados como el sueño, la sexualidad, el origen de la neurosis, el inconsciente, la paranoia, la homosexualidad o los mecanismos de curación en el psicoanálisis.

Ángel Garma, hombre joven de ciencia, comprometido con el desarrollo del psicoanálisis y también con los deseos de libertad y las aspiraciones democráticas que la II República significaba, e igualmente defensor del movimiento antifascista europeo.

Con el advenimiento republicano en abril de 1931, de modo pacífico y por la vía electoral, un buen puñado de intelectuales, artistas e investigadores organizados en la Agrupación al servicio de la República, presidida por José Ortega y Gasset, con magníficas intervenciones solidarias, de ostentada apoliticidad intelectualística -diría Bergamín-, que acudían como quien despierta de un largo letargo, a las expectativas y ansias de libertad que generó la II República española.

Garma se identificaba con las ideas republicanas y trabó gran amistad con un buen número personajes ilustres de aquellos intensos momentos. El 11 de 
febrero de 1933 firmó un manifiesto de la recién fundada Asociación de Amigos de la Unión Soviética tras «quince años de existencia de la república obrera rusa donde con grandes esfuerzos se ha venido levantando el acontecimiento económico y social más formidable del mundo moderno». El nombre de Ángel Garma al lado de Gregorio Marañón, Luis Jiménez Asúa, Pío del Río Ortega, Wenceslao Roces, Juan Medinabeitia, Jacinto Benavente, Pío Baroja, Victoria Kent, Valle Inclán, Juan Negrín, Manuel Machado, Concha Espina, Federico García Lorca, Clara Campoamor, Rodolfo Llopis y otros, hasta ochenta ilustres, de campos profesionales muy diferentes, pretendían desde su asociación colaborar para dar a conocer la verdad sobre lo que acontecía en la URSS, organizando múltiples y variadas actividades divulgativas «ante el anhelo de miles y miles de españoles que no pueden considerar ajena a sus preocupaciones humanas ni a los destinos del mundo la lucha por la sociedad nueva que ciento cincuenta millones de hombres están librando en el país de los Soviets».

En este mismo año, tras acceder Hitler al poder, Max Eitingon, su antiguo director del Instituto Psicoanalítico de Berlín, mantuvo una extensa correspondencia con Freud, buscando opciones posibles al acoso que recibía, incluidas las quemas de libros y archivos en Berlín. «¿Cuánto progresamos! En la Edad Media me hubieran quemado a mí; ahora se conforman con quemar mis libros». Eitingon acabó abandonando Berlín, yendo a Palestina donde organizó la floreciente Sociedad Psicoanalítica Palestina.

En la república española, en un contexto de notoria politización social, la izquierda se apropió del pensamiento psicoanalítico como una herramienta para la liberación sexual y política mientras que los sectores conservadores asociados a la Iglesia Católica lo rechazaban como inmoral. Algo muy similar a lo acontecido anteriormente con la apropiación política de las teorías del darwinismo y lo que ocurriría más tarde con la Teoría de la relatividad. En un Madrid agitado, con huelgas generales impulsadas por los socialistas, donde llegaban los ecos asturianos de una clase obrera dispuesta a la lucha armada y ahogada en 1934 en baños de sangre, con represalias por todo el territorio español y 30.000 personas encarceladas por motivaciones políticas, todo un ensayo de la cercana guerra civil. En esa ciudad, Ángel Garma inició algunos análisis terapéuticos, siendo su primer paciente como analista un hombre que sufría como consecuencia del rechazo amoroso de Federico García Lorca.

Después realizó otros análisis didácticos, contactando con los médicos interesados en la formación psicoanalítica, con intención de crear un instituto y asociación psicoanalíticos que pudieran asociarse a la API, similares a los que conocía en Berlín. 
En esa época estaba en boga la teoría psicoanalítica de la interpretación de los sueños, que los psiquiatras centraron en cuatro aspectos: el sueño como satisfacción de deseos, los mecanismos de elaboración del sueño, el simbolismo onírico y la técnica interpretativa. Pero en la psiquiatría española, lo realmente controvertido fue la teoría sexual, con visiones trasnochadas que equiparaban psicoanálisis y sexualismo, libido y sexualidad, sexualidad infantil y teoría biológica de los instintos. También se rechazaba la teoría freudiana de la libido. Garma desarrolló en esos años una intensa práctica privada como analista didáctico de un grupo de futuros psicoanalistas entre quienes sobresalieron Jerónimo Molina Núñez, José Solís y Mariano Bustamante. Este último llegó a ser un prestigioso neuropsiquiatra, el primer director del Hospital Psiquiátrico de Zamudio, y Jefe de los Servicios Neuropsiquiátricos provinciales de Bizkaia, adaptando la asistencia psiquiátrica a las modernas concepciones científicas, al tiempo que consideró la necesidad de disponer de hogares de tránsito, con función humanitaria, para los desarraigados y sin cobijo, sobre todo allí donde el progreso industrial lleva consigo una fuerte inmigración incontrolada.

«El psicoanálisis aumentó mi comprensión de la psiquiatría y, asimismo, la psiquiatría me sirvió mucho para comprender bien y evaluar la teoría y la práctica psicoanalíticas», diría Garma en 1983 en una entrevista con ocasión del cuadragésimo aniversario de la constitución de la Asociación Psicoanalítica Argentina. El movimiento psicoanalítico iba ganando muchos adeptos y en Madrid se iba constituyendo una «pequeña Viena» que se vería truncada por el golpe militar y la guerra civil posterior, lo cual le frustraría hasta llegar a considerar su asignatura pendiente y sería la razón que quizá justificó el apoyo que siguió prestando al naciente grupo de psicoanalistas madrileños de postguerra. Sólo Molina Núñez, amigo y anteriormente analizado por Garma, mantendría el nexo de unión con los intentos por reconstruir lazos con la API. Él, era médico militar, cercano al régimen, voluntarioso y siempre estuvo dispuesto a atraer a otros interesados, desde su cargo como Director del Hospital Psiquiátrico de Guadalajara. Pero no se crearía una organización psicoanalítica consolidada hasta más de veinte años después. Curiosamente, en esas décadas posteriores sorprendería que no impulsara de igual modo el análisis grupal o la psicología social que tanta pujanza tuviera en Argentina.

\section{Boda y exilio en Francia}

El 20 de abril de 1935 contrajo matrimonio con la joven de 22 años Simone Mas y Camps, en la iglesia de San Víctor, en Burdeos. Simone, mujer poco expre- 
siva de sus afectos, y que aún vive, era profesora de teatro ${ }^{13}$ y con ella tuvo dos hijas: Lucinda, que nació en Madrid en febrero de 1936 y llegó a ser una neurofisióloga del dormir y del soñar de renombre mundial, e, Isabel, en Buenos Aires. Ambas serían psicoanalistas y acabaron posteriormente ejerciendo en París, práctica que mantienen en la actualidad.

En España, la fractura entre quienes defendían el viejo régimen y los que soñaban con la revolución en su camino hacia la utopía, era tan grande que las personas moderadas de ambos lados no encontraban su espacio, engrosando las filas del desencuentro. El siguiente año, a punto de finalizar su libro $E l$ Psicoanálisis, la neurosis y la sociedad pidió la opinión de algunos capítulos a sus antiguos profesores y, ahora, amigos y colaboradores, Gregorio Marañón y José Ortega y Gasset. Estando de veraneo en Francia, recibió la noticia del pronunciamiento y comienzo de la Guerra Civil española, por lo que decidió no regresar a Madrid. En pocos meses había triunfado el Frente Popular en las elecciones, hervían los cuarteles, los señoritos falangistas de José Antonio Primo de Rivera practicaban el terrorismo en Madrid, cae el líder de la derecha José Calvo Sotelo y al día siguiente la conjura de los militares rebeldes iniciaba la despedida a la ilusión republicana.

Cinco días antes del estallido militar, dejó voluntariamente España, el mismo día en que Calvo Sotelo fue asesinado. «Se dio cuenta que asomaba una guerra civil y a él no le gustaba estar entre guerras, adelantó sus vacaciones y se fue a Francia», comentaba quien fuera su segunda esposa, la psicoanalista infantil Elisabeth Goode, más conocida posteriormente como Betty Garma. Añadiendo Garma: «me fui de España y no volví hasta dieciséis años después».

Cuando comenzó la guerra civil de 1936, el interés por el psicoanálisis estaba siendo impulsado por Mira i López (1896-1964) en Barcelona y por Rodríguez Lafora y Sanchís Banús en Madrid, aunque solamente había dos psiquiatras españoles que habían recibido formación y entrenamiento psicoanalítico: Ángel Garma y Ramón Sarró, en Berlín y en Viena respectivamente. Ambos eran de la generación que había nacido con el inicio del siglo, más receptiva que la anterior a las ideas freudianas.

Sarró se había analizado con la doctora Helene Deustch aunque, por sus resistencias, no llegó a cualificarse en psicoanálisis apartándose de la ortodoxia freudiana y acercándose a la clínica fenomenológica y a la psiquiatría antropoló-

13 Simone Mas i Camps, natural de Le Laurens de la Cabrerisse (Ande), nació en 1913, hija de Clement y Lucile. Fue profesora de teatro de Norma Aleandro, a quien llegó a decir: M'hijita, dedícate a otra cosa porque para esto no sirves. Norma, hija de actores, es directora de teatro y ópera, escritora de relatos breves, poemas y teatro, y actriz de teatro y cine («La historia oficial», «Gaby», «El hijo de la novia», «Seres», etc.). Ha llegado a comentar: Si alguien piensa que en Argentina todos somos actores o psicoanalistas..., jestá en lo cierto! (El País, 23-9-2003). 
gica. Volvería a Barcelona y en 1933 logró la plaza de profesor adjunto del primer catedrático de Psiquiatría de la Universidad española, el Dr. Emilio Mira i López. Resulta curiosa la similitud biográfica entre Sarró y Garma en los acontecimientos de su infancia. Ramón Sarró perdió a la madre a los tres años de edad y, tras ello, su padre se casó con la hermana de la madre. Por eso afirmaba haber tenido dos madres, aunque también añadía que «el trauma infantil imprime carácter según el psicoanálisis y, posiblemente, fue determinante para estar en Viena con Freud y acercarme al psicoanálisis».

En la década de los años treinta, Ángel Garma era un psicoanalista reconocido por la Internacional del Psicoanálisis, la API, vivía en la España republicana y era titular de la Asociación de Psicoanálisis Alemana, cuando ésta fue absorbida por el Instituto de Psicoterapia del Reich, ya bajo el rótulo de «Sociedad General Internacional de Psicoterapia» y reordenada según los principios de la «Revolución Nacional Alemana», dirigido por el primo del mariscal nazi Hermann Goering, el doctor Mathias Heinrich Göering, protestante convencido y nazi temible, cuya pretensión era uniformizar las diferentes corrientes ideológicas a fin de crear un psicoterapia alemana, específica, y para ello comenzó expulsando a los miembros judíos del Instituto tras decretar que, todos los miembros de la Sociedad deberían realizar un intenso estudio del Mein Kampf de Hitler, que debería servir de base a sus tareas. En ese año, Carl G. Jung tenía muchos seguidores en el movimiento psicoanalítico y, brillante y ario, había sido elegido presidente de la asociación de psicoanalistas por los psiquiatras de la Alemania nazi y fue el editor de la publicación oficial, Zentralblatt für Psychotherapie, hasta su renuncia en 1940, siendo su función principal el discriminar entre Psicología aria y Psicología judía destacando los valores de la primera, así como unificar todas las formas de psicoterapia e imbuirlas de los objetivos del nacional socialismo. En esos años las concepciones de Jung se tornaron más racistas, lo cual permitió a los racistas utilizar el «inconsciente colectivo» en sus tres dimensiones (la humanidad, la tribu y la familia) para sus fines, interpretando falsamente lo que Jung no escribió pero tampoco refutó. Con este panorama, Garma presentó su renuncia y pasó a ser miembro directo de la Asociación Psicoanalítica Internacional.

Como no deseaba participar en una guerra fratricida, aunque tenía simpatías republicanas, decidió permanecer primero en Burdeos y después en París. Allí acudió y se vinculó a las actividades del Instituto Psicoanalítico. Durante varios años (1931-35) había intervenido intensamente como terapeuta y conferenciante en Madrid y durante otros dos largos años lo haría en París. Comenzó a trabajar como psicoanalista en París, teniendo que dar clases de castellano para poder subsistir, e intimó con René Laforgue, Daniel Lagache, Sacha Nacht y otros psicoanalistas franceses, supervisando la formación analítica de Françoise Dolto junto a 
Rudolf Lowenstein. Dolto que, en ese año organizó los escritos de Psicoanálisis y Pediatría y que publicó en el año siguiente, en 1938, sería una de las figuras del psicoanálisis francés, que en los años cincuenta participaría en la aventura de la Société Française de Psychanalyse junto a Lacan y, años después, en la creación de la Escuela Freudiana de París. Allí conoció también a Marie Bonaparte, princesa de Grecia y Dinamarca por su matrimonio con Jorge I de Grecia, promotora del psicoanálisis francés desde que llegó a París en 1926 y artífice de dos hechos importantes: la salvaguarda de la correspondencia de Freud y Fliess así como del traslado de Freud y su familia de Viena a Londres en 1939. La posterior amistad entre Garma y Bonaparte hizo que la correspondencia fluyera en los años cincuenta. Por mediación de su amigo Rof Carballo conoció a un joven argentino en formación en el Instituto, Ernesto Cárcamo; si bien la ideología de Garma, agnóstico y de izquierda, le distanciaba de los psiquiatras muy ortodoxos. En Francia el clima político se deterioraba día a día, sus instituciones públicas apartaron la mirada ante los horrores del golpe militar español, reconocieron en 1937 a Franco, su gobierno de Vichy no tomaba posiciones firmes frente al fortalecimiento militar de Alemania ni ante el conflicto español. Ante ello tomó la decisión de emigrar a la Argentina donde tenía vínculos familiares, en vez de ir a Londres o a EE.UU. como hicieron otros psicoanalistas compañeros en París.

Tras el alzamiento contra el gobierno democrático de la II República, los militares y conservadores de ideología afín al fascismo italiano constituyeron un régimen totalitario que empujó a un importante movimiento migratorio de personas de todo tipo de condición y estatus social, siendo algunos países latinoamericanos los principales núcleos de acogida. El apoyo que muchos intelectuales e investigadores habían dado al gobierno republicano motivó que buena parte de ellos tuvieran que emigrar o exiliarse, convirtiéndose, en muchas ocasiones, en verdaderos embajadores de la II República. Fueron muchos quienes se desplazaron pero baste recordar algunos nombres conocidos que desarrollarían una gran labor creadora en el campo de la salud mental a nivel internacional y en los países de acogida: Emilio Mira, que durante la contienda civil fue nombrado Jefe de los Servicios Psiquiátricos de los Ejércitos Republicanos, difundió la psicología aplicada en Brasil y resto de la región latinoamericana siendo creador del test miokinético, y fundador del ISOP (Instituto de Seleçao e Orientaçao Professional) y, en 1948, los Arquivos Brasileiros de Psicotécnica; Ángel Garma, figura clave en el desarrollo del Psicoanálisis Institucional en Argentina, desarrollando un vasto programa de investigaciones en temas psicosomáticos y psicoanalíticos; Mercedes Rodrigo, educadora y psicotécnica, se marchó a Colombia en 1939 y fundó un Instituto de Psicología Aplicada y organizó la titulación en Psicología (1948). En 1950, fue obligada a salir del país y se marchó a Puerto Rico, donde continuó tra- 
bajando; En México, Gonzalo Rodríguez Lafora desde la neuropsiquiatría y José Peinado desde la psicología clínica, lograron una adecuada política sanitaria de la salud mental; Guillermo Pérez Enciso, Francisco del Olmo y César de Madariaga, en Venezuela; Antonio Román Durán, en Guatemala, etc. Todos ellos contribuyeron a la organización y desarrollo de la psicología, la psiquiatría y el psicoanálisis en toda la comunidad castellano parlante, constituyendo toda una red de instituciones, sociedades científicas, publicaciones, formación reglada, etc., que ellos mismos pretendieron y no lograron en España. Para la psicología, psiquiatría y el psicoanálisis este exilio masivo tuvo efectos devastadores en el territorio español, lo contrario que lo logrado en el continente americano.

Quienes quedaron en el Estado español convivieron con los intentos de homogenización y rectificación ideológica, volviendo a retomar la filosofía escolástica y desnaturalizando los progresos en las disciplinas científicas, las ciencias de la salud mental entre ellas. Baste recordar que Antonio Vallejo Nájera, primer catedrático de Psiquiatría bajo el nuevo régimen, entre sus méritos tenía por ejemplo el haber investigado sobre «La predisposición institucional al marxismo y sus bases psicológicas» utilizando en sus experimentos de laboratorio como cobayas a milicianos y a miembros de las Brigadas Internacionales que habían sido detenidos. Dirigió un estudio en 1939 que analizaba El psiquismo del fanatismo marxista en los prisioneros de guerra norteamericanos. Fruto de aquellas investigaciones cabe destacar conclusiones como «las íntimas relaciones entre marxismo e inferioridad mental ya las habíamos expuesto anteriormente [...], la segregación de esos sujetos desde la infancia podría liberar a la sociedad de plaga tan terrible». Una nueva psiquiatría «nacional», tras la depuración o exilio de las personalidades más notorias, de ideas republicanas o liberales la mayoría, se abría paso ocupando cargos relevantes en las universidades y hospitales.

\section{8: Buenos Aires, el exilio definitivo}

Tras la invasión de Austria, Freud decidió abandonar su patria. Entre su gran amiga Marie Bonaparte y su hija Anna Freud revisaron todos los papeles para decidir qué llevaban a su exilio en Londres, lo cual ocurriría en junio de 1938. Ese mismo mes, Ángel Garma, con su formación terminada, escapando de la guerra en su país y de la inminente II guerra mundial, decidió residir en Buenos Aires, donde llegó en barco el 24 de junio de 1938. Este día de junio, coincidiendo con su fecha de nacimiento, para muchos es el origen de lo que sería la Asociación Psicoanalítica en la Argentina. Allí, en Buenos Aires, habían nacido dos de sus hermanos y una hermana estaba casada con un médico argentino, y también allí 
había fallecido su padre. Además, en esa ciudad disponía de algunos bienes que facilitaron su instalación durante los primeros años.

Buenos Aires y su área de influencia (ciudad de seis millones de habitantes, opulenta y sofisticada culturalmente), le recordaba a Ángel Garma lo mejor de Madrid en el cual había vivido. Tenía un medio «humano libre, inteligente y en contacto con la realidad, con pocos sometimientos superyoicos». Era un lugar idóneo para acoger y difundir en su seno algo tan novedoso como el psicoanálisis de la época. La ciudad, con una importante clase media, donde los inmigrantes europeos ${ }^{14}$ estaban ya integrados, con ideas liberales y enfrentada política e ideológicamente a los valores conservadores y ultracatólicos de las clases más tradicionales de la sociedad argentina, incluidos grupos nazi-fascistas, antisemitas y totalitarios, algunos en la oficialidad del ejército que ya en 1930 llegaron a protagonizar el primer golpe militar del siglo en Argentina.

«Los argentinos que fundaron su nación no tenían prejuicios, ni estructuras rígidas, emigraron con la finalidad de defender la vida y, en un país joven, estaban más abiertos a las ideas nuevas. Su personalidad era más sencilla, con menos exigencias del entorno (...). Este pueblo, por otro lado fóbico y melancólico, que vivía muy unido a la familia en las extensiones de la Pampa» se convirtió en buen caldo de cultivo para la eclosión psicoanalítica de la que un responsable principal fue Garma. En Buenos Aires, el psicoanálisis halló un espacio en la cultura popular. Se lograba la convergencia de un discurso más abierto sobre sexualidad con nuevas formas «científicas» del conocimiento y favorecía la modernización de las costumbres sociales. El psicoanálisis atraía por ser moderno y se legitimaba por sus lazos con la medicina, por ser un recurso para lograr más salud.

En 1939 moría Sigmund Freud, en el exilio, siendo ya famoso y perseguido por los nazis que llegaron a quemar sus libros. En Buenos Aires hubo un homenaje organizado por el Colegio Libre de Estudios Superiores, una especie de universidad paralela, y poco después Jorge Thénon -nieto de inmigrante vasco-francés- coordinó dos cursos sobre Freud y el análisis crítico de su obra, lo que aportó varias conferencias sobre psicoanálisis y medicina. Thénon, inspirador de la psicología y psiquiatría pavlovianas ${ }^{15}$ en Argentina, autor de un libro sobre la neurosis obsesiva, que mereció una cálida respuesta de Freud, estuvo interesado por el psicoanálisis tras sus experimentos con la hipnosis, acabó siendo un frontal opositor al psicoanálisis, denunciándolo como método burgués

14 Entre 1840 y 1940 fueron 7.400 .000 el número de inmigrantes, la mayoría italianos (44\%) y españoles $(33 \%)$, representando el crecimiento debido a la inmigración un $29 \%$ del total.

15 Los comunistas eran, en general, partidarios de la reflexología como su terapia. Pavlov experimentó con perros, principalmente, explicando lo primitivo y los reflejos condicionados pero no pudiendo ayudar a resolver los conflictos emocionales de las personas. De ahí que los psiquiatras y psicólogos próximos al Partido Comunista argentino acabaran yendo a psicoanalizarse. 
anticientífico, sobre todo cuando tuvo conocimiento de que iba a nacer una asociación psicoanalítica en Argentina. Diez años antes, en su tesis doctoral, ofrecía un gran conocimiento de la teoría psicoanalítica, pero tras coincidir con los medios intelectuales cercanos al Partido Comunista francés y seguidor de la psiquiatría oficial francesa que expresaba su rechazo al psicoanálisis, algunos dicen que, como reflejo de la decisión soviética de 1929 de poner fin a las experiencias psicoanalíticas realizadas en Rusia tras su revolución, dio un vuelco a sus postulados teóricos.

Garma en su primer año optó por no realizar actividad profesional alguna con pacientes y se dedicó a revalidar su título médico en la Universidad Nacional de La Plata realizando una tesis doctoral sobre el Psicoanálisis de los sueños. Conocía las dificultades de su analista Theodor Reik, o de Eugénie Sokolnicke y otros extranjeros en París, por no ser médicos habilitados y decidió ponerse a cubierto de cualquier contingencia. Lo logró en agosto de 1940. Su tesis doctoral de 1940 fue la primera en Latinoamérica referida a un tema psicoanalítico, y fue sobre El psicoanálisis de los sueños.

Poco antes de julio de 1936 se había organizado la sección hispanoamericana de la Alianza de Intelectuales Antifascistas con quienes colaboró Ángel Garma tras su llegada a aquel país. La intelectualidad antifascista porteña también organizaba otros emocionados encuentros como ocurrió desde el Centro Republicano Español donde disertaban ilustres psiquiatras refugiados de la guerra civil: los también criminólogos Emilio Mira i López y Luis Jiménez de Asúa -éste llegó a ser el presidente del Centro en los años cuarenta tras su buena imagen al haber sido redactor de la Constitución de la II República española- y el propio Ángel Garma. Este último mantuvo su republicanismo durante toda su vida. «Entre el consultorio de papá y mama siempre estaba la bandera republicana», me comentaba Carmen Garma.

Garma había ido a Berlín a formarse con el deseo de volver a su tierra y ejercer con el bagaje aprendido. Pero primero la incomprensión de algunos y después la madre patria le expulsaron. No obstante, siempre tuvo la ilusión de que sería temporal, de ahí que renovara constantemente sus pasaportes a través de la embajada en Buenos Aires.

El rechazo de todo lo que significara guerra y destrucción para buscar lo que expresara vida, creación y paz, sintonizaba en Ángel Garma con su carácter lo cual se reflejaría en sus teorías psicoanalíticas pues, aunque crítico, era gran conocedor de la obra de Freud repitiendo en varias ocasiones que «las ideas de Freud habían cruzado el charco». Además se sentía animado por el viento favorable del movimiento psicoanalítico argentino y en América latina donde «las resistencias al psicoanálisis son bastante menores que las que tuve que experimentar en España...». 
HISTORIA DE LA PSIQUIATRÍA

Pero siempre aspiró a retornar a una España republicana donde el psicoanálisis alcanzara, en el ámbito internacional, el lugar que el golpe militar y la guerra civil impidieron.

\section{2: funda la APA}

Al llegar Ángel Garma a Buenos Aires, llevaba una importante formación psicoanalítica, una firme convicción en sus puntos de vista científicos y una poderosa personalidad creadora, siendo él mismo la base del movimiento psicoanalítico y figura fundamental en el desarrollo de las décadas iniciales.

La intensa producción editorial argentina, la mayor del mundo de habla hispana, acogió calurosamente a Garma y a otros autores cercanos al psicoanálisis como Emilio Mira i López o Luis Jiménez de Asúa. Ese fulgor editorial argentino fue paralelo a la retracción española en la edición de libros debido al enorme éxodo de intelectuales y a las consecuencias de la guerra civil. A partir de 1940 colaboró con diversas revistas especializadas: La revista de la Asociación Médica Argentina, Psicoterapia, Index (revista bibliográfica que funcionaba como publicación del Hospicio de Las Mercedes), Psiquiatría y Criminología (sucesoria de la legendaria Archivos), la Revista de Psicoanálisis, etc. La editorial El Ateneo de Buenos Aires publicó en ese mismo año una segunda edición de su libro Psicoanálisis de los sueños y poco más de un año después, el tratado $E l$ Psicoanálisis. Tres años después, la editorial realizaría un convenio con la asociación psicoanalítica para la publicación de una Biblioteca de Psicoanálisis. Estas obras actuaron como operadores del crecimiento y presencia entre médicos, psicólogos e instituciones existentes o de creación subsiguiente. En este sentido, la carta de Ernest Jones del 16 de febrero de 1941, en respuesta a una solicitud expresa de Garma, tuvo un valor testimonial de primer orden.

Junto a Arnaldo Rascovsky, a quien analizaría desde 1939 y en los años siguientes, y a Pichon Rivière que comenzó su análisis unos meses más tarde, puso en marcha un importante movimiento psicoanalítico de aquel país. Con Pichon Rivière, Rascovsky, Cárcamo, Thenon, Székely y otros, tras algunas conversaciones, decidieron no apresurarse en la constitución de una sociedad psicoanalítica.

Aquel recio pionero, un tanto tosco, fue autor de numerosas obras psicoanalíticas en las que impresionaba por su lucidez y por los muchos ejemplos coloristas que acompañaban a sus reflexiones. Solía insistir en que sus concepciones psicoanalíticas se apoyaban plenamente en Freud, sin embargo, no se consideró un «freudiano» ortodoxo, sino que mantuvo opiniones propias basadas en su experiencia. Aunque hay comentarios que también apuntan en sentido contrario. Se 
HISTORIA DE LA PSIQUIATRÍA

dice que Béla Székely, húngaro que dirigía un instituto de salud mental sostenido por la colectividad judía, y se consideraba así mismo como el único serio para la práctica del análisis, comentó a Marie Langer: «Si usted quiere trabajar creativamente, quédese conmigo, pero si quiere análisis ortodoxo y ganar dinero, entonces vaya con el doctor Garma». En aquel 1941 Langer acudió donde Ángel Garma.

Su labor de terapeuta, didacta y propulsor fue acompañada de un intenso trabajo como investigador. Sus originales aportaciones sobre temas muy variados alcanzaron una gran difusión. Escribió sobre la úlcera gastroduodenal, el dolor de cabeza, la terapéutica psicoanalítica, la situación traumática de los sueños, el sadismo y masoquismo, etc., sin gala de erudición. Por eso entendía que lo más analítico era crear la transferencia positiva hacia el movimiento a favor del psicoanálisis a través de su estilo sencillo.

Hasta el inicio de su obra, en los años treinta, no había nadie realmente solvente en el campo del psicoanálisis. Una revisión de los contenidos de Archivos de Neurobiología en su primera época, muestra que publicaron en ella prácticamente todos los psiquiatras y neurólogos de la época con cierta inquietud científica. Entre ellos, de 1930 a 1935, hay ocho artículos de Garma con temas tales como «Interpretación psicoanalítica de un gesto de Santa Teresa», «La realidad y el Ello en la esquizofrenia»o «Paranoia y homosexualidad». Curiosamente, los primeros trabajos sobre psicoanálisis los publicó en alemán ya que le resultaba sencillo el lenguaje científico. También sus primeras conferencias las dictó en esa lengua. Ya en 1932 recibió una carta de Freud felicitándole por sus trabajos (Verdienstvollen Arbeiten). Consecuencia de la guerra civil dejó de editarse en 1936 y así permaneció hasta que en 1954, Gonzalo R. Lafora, tras superar no pocos obstáculos, logró reiniciar la publicación de Archivos de Neurobiología.

En Buenos Aires, Ángel Garma, se reunía con el grupo dinamizador del psicoanálisis. Arnaldo Rascovky (1907-1992), que había nacido en Córdoba, médico judío que provenía de una familia de inmigrantes rusos que trabajaba en el servicio de Neurología, Psiquiatría y Endocrinología del Hospital de Niños «Ricardo Gutiérrez» en Buenos Aires, y había resultado ser un exitoso pediatra y endocrinólogo; Enrique Pichon Rivière (1905-1979), nacido en Ginebra, Suiza, emigró al Chaco y luego a Corrientes donde sus padres crearon una escuela cuando él era niño. Gran conocedor de los ambientes culturales y bohemios porteños, pionero en el uso de la terapia electroconvulsiva, que trabajó muchos años en el Hospicio de las Mercedes, actual hospital psiquiátrico Borda; Marie Glas de Langer (19101987), nacida en Viena, con buena posición económica y social, comenzó su psicoanálisis en 1933 con Richard Sterba, siguiendo su formación en el Instituto Psicoanalítico vienés. Ante la persecución nazi salió de Austria, colaboró con los 
republicanos españoles en la guerra civil, después hubo de huir, fue a Uruguay y, por fin, a Buenos Aires en 1942. Deseosa de incorporarse al grupo psicoanalítico que estaba formándose se entrevistó con Garma, quien la incorporó de inmediato a su grupo; Celes Cárcamo (1903-1990), miembro de una familia aristocrática terrateniente, de ascendencia vasca, que había vuelto a Buenos Aires en 1939 tras realizar en París su formación en el Instituto Psicoanalítico de aquella ciudad, analizado por Paul Schiff, trabajó en el hospital Durand de Buenos Aires y antes en el hospital de Clínicas. De vasta cultura humanista, estaba muy preocupado por insertar el psicoanálisis en los ámbitos culturales, acorde a sus intereses por la filosofía, arte y religión; Guillermo Ferrari Hardoy que, aunque miembro del primer grupo, no llegó a participar en la recién creada asociación ya que poco después emigró a EE.UU., si bien en el Acta fundacional aparecen las firmas de todos ellos. Los pioneros leían a Freud de modo acelerado, incluso en un solo verano. Todos se conocían de las tertulias literarias y existía una importante coincidencia de ideas políticas. Garma había colaborado con el Centro Republicano, Pichon Rivière, con su pasado socialista, Marie Langer que perteneció al Partido Comunista en Viena y, los demás, también eran buen reflejo del ideario cercano a los grupos liberales antiperonistas. En aquel 1942, de enorme tensión militar por una guerra mundial, inicialmente europea, todos ellos, Garma, Rascovsky y Pichon Rivière, junto a otros psiquiatras residentes en Argentina, Cárcamo y la psicoanalista austríaca Marie Langer, fundaron la Asociación Psicoanalítica Argentina (APA), la primera de Latinoamérica, que tuvo lugar en Buenos Aires. Y todos ellos eran médicos, lo que orientaba a pensar en una clara relación entre psicoanálisis y medicina psicosomática, tal y como confirman los propios textos producidos en la primera época.

El 15 de diciembre de 1942, los miembros de la APA eligieron un comité ejecutivo, con Garma como presidente, Cárcamo como secretario y Rascovsky designado director de publicaciones. Decidieron iniciar todos, como miembros adherentes, condicionando acceder a la categoría de miembro titular y didáctico a la presentación de un trabajo científico.

Se reunían en su primera sede, en la calle Juncal 655, y antes lo habían hecho en la casa de Cárcamo, en la calle Perú. Fueron estableciendo las líneas generales de las futuras actividades psicoanalíticas para la sociedad que acababan de constituir. A sugerencia de Garma acordaron no solicitar el reconocimiento internacional hasta que cada participante tuviera un análisis suficiente, limitando su relación, además, al plano estrictamente profesional.

En una asociación pequeña como era aquella, los «análisis cruzados» resultaban ser de obligada necesidad. Simone Mas, la primera mujer de Garma, se analizaba con Cárcamo. En un momento dado, Garma sintió la necesidad de analizarse y lo hizo con Marie Langer, a quien él había analizado un tiempo. Langer 
sintió similar necesidad y se analizó con Cárcamo. El analista de Garma estaba en análisis con el de la mujer de Garma y todos eran psicoanalistas didactas en la APA. Garma analizó a Arnaldo Rascovsky y Pichon Rivière; luego vendrían Simón Wencelblat, Flora Scolni, Matilde Rascovsky y Arminda Aberastury. Cárcamo lo hizo a Ferrari Hardoy, Luisa Gambier y Luis Rascovsky. Ilustres analizados, en ocasiones, con análisis muy breves si fueran comparados con el tiempo prolongado actual, que convirtieron a Garma en un didacta, a pesar de que no adquirió esa posición en París ni en Madrid. En aquella época, la terapia psicoanalítica se solía desarrollar en cuatro o cinco sesiones de una hora a la semana y durante unos tres años de duración en el caso de pacientes que valoraban la posibilidad de ser psicoanalistas didactas. Balán ha llegado a señalar que Garma tuvo mayor dependencia de sus analizados que viceversa, en la medida que en los primeros años ellos nutrían de pacientes su consultorio. En la realidad, la relación con el maestro resultaba equitativa: lo que uno tenía de experiencia y reconocimiento externo, lo aportaron los otros mediante la capacidad para movilizar recursos en el medio local.

Ángel Garma y Celes Cárcamo, dos analistas con formación completa y afiliación a la Asociación Psicoanalítica Internacional (API), ofrecían credibilidad al proyecto. Mantuvieron reuniones los miembros más destacados del grupo inicial, junto con otros médicos que lo habían practicado de modo informal o habían escrito sobre el psicoanálisis como Gregorio Bermann o Jorge Thénon. Pero ninguno de los psiquiatras que habían mostrado interés por el psicoanálisis en la década anterior, ni siquiera los miembros de la sociedad de Psicología Médica y Psicoanálisis se sumó a la APA. Bermann, Thénon, Ramón Beltrán y Pizarro Crespo pretendieron compatibilizar el psicoanálisis con sus posiciones ideológicas respectivas compaginándolo con otras teorías psiquiátricas. Los médicos de izquierda querían renovar la práctica terapéutica y sugerían que el psicoanálisis podía ser una buena herramienta para la crítica social. Tras la fundación de la APA, generalmente los psicoanalistas se hallaban apartados del establishment médico, no participando en sus conferencias ni en sus publicaciones. Sin embargo, los miembros de ésta sí se fueron integrando en aquélla en las décadas posteriores.

Habían escrito a Ernest Jones, presidente de la Asociación Psicoanalítica Internacional detallando los pasos dados en Argentina. Con él, Garma mantuvo intenso contacto epistolar durante los años de la guerra mundial. Jones respondió a Cárcamo el 12 de diciembre de 1942 señalando que a los miembros del Consejo de la API, a quienes había consultado, les había impresionado favorablemente las cartas de Cárcamo y de Garma, por lo que les trasmitía la aceptación provisional. Fue el 15 de diciembre de 1942 cuando se firmó el acta inaugural como Sociedad Componente aunque, de hecho, ya venía funcionando sin reconocimiento interna- 
cional. En el mismo mes, el gobierno de la República Argentina confirió el estatus legal a la Asociación Psicoanalítica Argentina (APA). Reconocidos como grupo analítico filial de la Internacional de Psicoanálisis, en espera de la ratificación que daría el primer congreso internacional a realizar cuando finalizara la guerra en curso. Seis años antes, ya existía un círculo psicoanalítico informal que se reunía con regularidad los domingos por la tarde en el departamento de Arnaldo y Matilde Rascovsky. Era en un piso de la avenida Santa Fe 2982, donde Arnaldo Rascovsky tenía su consulta como pediatra. Allí se juntaban con los hermanos Wencelblat, Jaime Salzman y Flora Scolni; los Pichon Rivière, Enrique y Arminda, que se habían casado en 1937; Luisa Gambier, luego casada con Álvarez de Toledo y una de las pocas médicas del grupo inicial; Alberto Tallaferro, médico joven, así como Teodoro Schlossberg, endocrinólogo que realizaba prácticas alternativas en su especialidad. «Eramos un grupo selecto de gente culta e inquieta de clase media acomodada, de buena voluntad. Nos sacrificamos, trabajamos y estudiamos duramente para difundir y enseñar el psicoanálisis. Eramos progresistas. Ofrecíamos sabiduría, salud física y mental a Buenos Aires y a las Américas... hablo con ironía pero no reniego de esa época... nos proponíamos salvar el mundo a través del psicoanálisis... nos sentíamos una elite intelectual», diría Langer años más tarde.

Durante la década de los años treinta, la doctrina freudiana tuvo gran atracción en un número creciente de psiquiatras, no como método exclusivo sino como herramienta que podía ser agregada a técnicas y teorías más tradicionales $\mathrm{y}$, a veces, combinada con ellas. Incluso quienes veían el psicoanálisis con desaprobación reconocían que, al menos, algunos conceptos de origen psicoanalítico merecían ser tomados en serio. En 1940, dentro de la Asociación Médica Argentina, se organizó la Sociedad de Psicología Médica y Psicoanálisis, impulsada por Juan Ramón Beltrán, profesor de historia de la Medicina, derechista próximo a los militares antidemocráticos y, también, propagandista del psicoanálisis que no se había analizado ni ponía en práctica las técnicas freudianas pero que junto a otros psicoanalistas «silvestres» (sin entrenamiento formal según las reglas internacionales) tendían a ocupar los pocos espacios públicos que se iban abriendo a la nueva profesión. Antes, en diciembre de 1939, pretendió fundar la Sociedad Argentina de Psicoanálisis basándose en la presencia de estudiosos del psicoanálisis. Desde el comité editorial de la revista Psicoterapia (revista de Psicoterapia, Psicología médica, Psicopatología, Psiquiatría, Caracterología, Higiene Mental), fundada en 1936 por Gregorio Bermann (psiquiatra, forense y toxicólogo en la Universidad de Córdoba, Argentina, preocupado por la aplicación del psicoanálisis a la criminología) sólo publicó cuatro números antes de partir para España para ofrecer sus servicios al ejército republicano como voluntario en las Brigadas Internacionales. 
Antes, Bermann estuvo influenciado por el psicólogo y filósofo marxista húngaro-francés Georges Politzer, quien estuvo interesado un tiempo en el psicoanálisis para rechazarlo posteriormente. En 1948 Bermann escribió el prólogo del libro Principios elementales de filosofía, de Politzer, texto que en los años sesenta y setenta fue verdadero «catecismo» en numerosos círculos marxistas a ambos lados del Atlántico. La revista Psicoterapia era de tendencia claramente progresista y de izquierda, aunque la participación de algunos conservadores y de derechas demostraba que existía un espacio para el discurso civil al tiempo que era expresión de ideas y valores que buscaban la modernización de la psiquiatría, y también desde otras revistas e instituciones expresaban sus preferencias políticas aunque el valor de las teorías científicas discutidas en ellas se justificaba dentro de la lógica del discurso científico. La revista, además de plantear la necesidad de establecer la ruptura con la psiquiatría tradicional, fue la primera revista argentina que publicó artículos de Freud y de Jung traducidos al castellano. También en Psicoterapia, Ángel Garma publicó sus primeros artículos en Argentina ${ }^{16}$, en 1936, año de la primera tentativa de articulación entre marxismo, psiquiatría y psicoanálisis desde la propia revista y a través de la psiquiatra Paulina Rabinovich ${ }^{17}$ que trazó un paralelismo entre el inconsciente freudiano y los reflejos inconscientes de Pavlov y, además, comparó el empirismo del Psicoanálisis con el de la psicología de Pavlov así como el valor acordado en el determinismo de la vida psíquica por Freud y el determinismo pavloviano.

La APA fue motor de diversos cursos de formación universitaria, de congresos y de otras reuniones científicas en el campo psicoanalítico, y, Garma, como primer presidente de la institución, asumió las responsabilidades de su organización.

Obtuvieron un local y, tras esto, didactas y candidatos comenzaron los seminarios de formación tomando como primera tarea una lectura colectiva de la obra de Freud, coordinada por Garma. Un año más tarde comenzaron a editar la Revista de Psicoanálisis, primera publicación de esta materia de habla castellana y que mantendría su edición hasta la actualidad. Esta publicación que fundó y dirigió Arnaldo Rascovsky, incluyó en su número inaugural «Primeros estadios del conflicto de Edipo y de la formación del superyo», el octavo capítulo de El psicoanálisis de niño (1932). Las firmas de Arnaldo Rascovsky, Celes Cárcamo, Ángel Garma, Franz Alexander y Melanie Klein dieron contenidos a ese primer ejemplar y después sería el principal marco donde Garma fue reflejando sus escritos más valiosos.

16 Ángel Garma, «La proyección y la vuelta de los instintos contra el Yo en el sueño», Psicoterapia, 1936, n. ${ }^{\circ}$, «Evolución y nuevos problemas en la teoría», Psicoterapia, 1936, n. ${ }^{\circ} 3$.

17 Paulina Rabinovich, «El psicoanálisis y los reflejos condicionados», Psicoterapia, 1936, n. o 3, pp. 66-74. 
Muchos de quienes fueron sus compañeros en Berlín y París, donde el psicoanálisis se había introducido en las escuelas de medicina y en los claustros filosóficos, habían huido o emigrado. Las leyes raciales y la repulsa al nazismo favorecieron que numerosos intelectuales, sociólogos, psicoanalistas, filósofos, y médicos residentes en el este y oeste americano se acercaran al psicoanálisis difundiendo su interés. Garma fue el puente de quienes se habían refugiado en EE.UU. huyendo de Europa. Otto Fenichel le escribió ya el 25 de octubre de 1939 solicitando su colaboración en el Psychoanalitic Quarterly aportando sus comentarios o la revisión de publicaciones especiales. Durante la década posterior fueron muchas las propuestas de trabajo, de envío de publicaciones, ofrecimientos de colaboración, contrataciones para dar cursos y seminarios y, por la constancia y sutileza de Garma, el ofrecimiento de obras para ser publicadas por los editores locales. Fue nutrida la correspondencia con notables del psicoanálisis como Otto Fenichel, Theodor Reik, Franz Alexander, Thomas French, y Karl Menninger, quien desde Topeka, en Kansas, dirigía una prestigiosa fundación que dio cabida a todos estos ilustres, y también invitó, varios años después a Ángel Garma y a Betty Goode a exponer sus experiencias y métodos de trabajo. La fecunda interacción se mantuvo durante décadas. Así es como cada mensaje, cada sugerencia se convertía en ofrecimientos, trabajo, conferencias, contactos, ediciones que daban relevancia a lo que desarrollaban en aquellos momentos con tanto empeño: instalar el psicoanálisis como práctica de terapia y de transformación de metodologías creativas.

Al mismo tiempo, la Revista de Psicoanálisis fue publicando importantes artículos de Abraham, Ferenczi y Ernest Jones, no menos que los del mismo Sigmund Freud, de Anna Freud, Richard Sterba, Franz Alexander, Fairbairn, Winnicott, Strachey, Fenichel, Tausk, Marie Bonaparte, Hartmann, Melanie Klein y de otros grandes psicoanalistas de la primera mitad del siglo XX, al lado de los estudios de la pléyade argentina, los Cárcamo, Garma, Rascovsky, Marie Langer, Pichon Rivière y poco después de Racker, Grinberg, Resnik, Zac, Liberman, Álvarez de Toledo y Bleger por citar sólo a los más notorios en su producción. Distribuida originariamente de modo gratuito entre profesionales, médicos y abogados principalmente, para cuando su segundo número vio la luz, más de dos centenares de suscriptores auguraban el considerable incremento en los años siguientes.

En mayo de 1943, Ernest Jones le envió un escrito felicitando por la formación e inicio de la sociedad psicoanalítica de Buenos Aires (sic) deseando los mejores éxitos de la Revista. «Será la primera publicación en lengua española dedicada al psicoanálisis, y marca el comienzo de una nueva era del psicoanálisis para los países de habla hispana. Para los contactos internacionales en nuestro tra- 
bajo, el alemán, todavía deseable y formalmente indispensable, está cediendo el primer lugar al inglés, y hay que esperar que la colaboración política entre los países de habla española e inglesa se incrementen y sea acompañada por una estrecha colaboración en nuestro trabajo científico». Los horizontes sobrepasan las cuestiones inherentes al psicoanálisis y devienen una estimación sobre el curso de los acontecimientos culturales mundiales.

Tres años después fundó también el Instituto Psicoanalítico de Buenos Aires, siendo su director durante largos períodos, y actuando como profesores los pioneros de la Asociación, docentes y buenos conocedores de la obra de Freud que también aportaron un buen número de contribuciones originales. La APA incluyó al Instituto, más tarde llamado Instituto Ángel Garma, como centro de docencia en psicoanálisis, cuya función es la formación de analistas cumpliendo los requisitos que fija la Asociación Psicoanalítica Internacional; inspirado en el de Berlín donde Garma hizo su formación, y apoyándose en tres tipos de actividades: el análisis didáctico, los seminarios y los controles o supervisiones.

El grupo inicial era una verdadera familia de acogida. A los seis fundadores se sumaron los amigos de aquel anterior círculo informal y también las esposas de tres de ellos. Los representaban un microcosmos de la sociedad porteña. Trabajaban en una institución analítica que definían como una verdadera subcultura. Hablaban con una jerga común, tenían comportamientos similares, con relaciones interpersonales, en general, endogámicas: sus amistades también eran psicoanalistas, estaban juntos los fines de semana y vacaciones, tenían escasos vínculos con la medicina tradicional, con frecuencia elegían pareja entre ellos, las conversaciones giraban en torno a la profesión y observaban el mundo desde la atalaya del psicoanálisis. Pertenecían a una generación formada en un período de crisis económica y agitación política. Algunos provenían de familias que habían respondido a la depresión económica de los años treinta emigrando de las zonas rurales pauperizadas a Buenos Aires donde lograron una buena posición social. Otros, eran emigrados recientes que llegados de Europa buscaban un lugar seguro frente a un mundo que se había deshecho ante sus propios ojos. Para todos ellos, el psicoanálisis llegó a ser la pasión central de sus vidas. Creían en él fervientemente, como vehículo de la liberación de la humanidad y como tratamiento del sufrimiento individual y así creció en sus mentes analizadas. Por aquellos años, ya separado de su primera mujer, conoció a Elisabeth Goode, quien sería su colaboradora el resto de su vida.

Hubo que esperar a mediados de los años cuarenta para recuperar unas elecciones democráticas, que dieron la victoria a un naciente movimiento de masas, el peronismo. 
Durante el gobierno populista de Perón con sus «descamisados» ${ }^{18}$, los integrantes de la APA debieron mantener un bajo perfil político en una década de antipatía nacionalista contra el imperialismo económico británico y norteamericano y contra la tradicional hegemonía cultural europea. La política de Perón representaba una amenaza para las tradiciones de la clase media europea y para la comunidad de artistas, científicos y psicoanalistas, también de raigambre europea. Pero a pesar de aquel populismo del gobierno de Perón, del que muchos recordaran lo de libros no, zapatillas sí, Buenos Aires ofreció un marco cultural apropiado al crecimiento del Instituto de Formación Psicoanalítico de APA que se constituyó en el más prestigioso centro de formación psicoanalítica latinoamericano. La APA hizo grandes esfuerzos por difundir el psicoanálisis, no sólo en el medio profesional sino también en el gran público. La Revista de Psicoanálisis se vendía en las librerías de Buenos Aires que poseían una clientela interesada en artes y ciencia sociales. Por ello era necesario poseer un bajo perfil para que la joven y pujante Institución no tuviese riesgo alguno.

Así como ocurrió con los inmigrantes cuyo abolengo desciende de los barcos que los transportaron desde Europa, sucedió también con los iniciadores y fundadores del movimiento psicoanalítico, buena parte de ellos europeos, con algunas excepciones como Raskovski y Pichon Rivière (europeo, emigrado en la infancia) que provenían de las provincias argentinas.

Con anterioridad a esta fundación, la Argentina había albergado a una veintena de psicólogos y psiquiatras centro-europeos exiliados de la segunda guerra mundial, en su mayoría judíos, perseguidos por el régimen de Hitler y con el explícito deseo de no dejarse matar y huir de la involución paranoica y criminal que significó el nazismo. Aunque todos ellos, junto a psiquiatras, escritores, filósofos y educadores argentinos fueron iniciadores de una cultura psicoanalítica en el país, casi ninguno se integró en la APA, fenómeno que resulta de difícil explicación.

Si bien la idea psicoanalítica fue aceptada desde sus comienzos por la intelectualidad argentina, por su idealización fue muy temida y rechazada en otros medios. La libertad para pensar y la búsqueda de la verdad que ella propone hizo que le adjudicaran ideas comunistas, radicales, populistas, individualistas, antirreligiosas, etc., en un país extremadamente católico. A ellos se unieron los psiquiatras que se vieron atacados en el ejercicio de su profesión. El psicoanálisis como toda idea nueva contiene una fuerza disruptiva que violenta en menor o mayor grado la estructura del espacio en que se manifiesta. En este caso, violentó la

18 Cuando el general Juan Domingo Perón pareció caer en desgracia, la víspera del 17 de octubre de 1945, sacó en portada el diario Crítica una foto de los partidarios de Perón con un epígrafe que pretendía la denigración: «iDescamisados!» Este término fue adoptado inmediatamente con orgullo por los peronistas. 
estructura psiquiátrica preexistente. Embarcados en la denuncia antifascista y coincidiendo con el triunfo antinazi, el psicoanálisis lograba nuevos desarrollos. Muy pronto las dictaduras también le temieron y, durante el gobierno de Perón, los ateneos y seminarios de la APA contaron con la compañía de un policía, amparados por una ley que impedía reuniones numerosas.

Siempre explicando el psicoanálisis. «Realmente he trabajado muchos años en esta especialidad, tanto desde el punto de vista terapéutico y de investigación, pero si he sido capaz de hacerlo es porque me he encontrado con personas parecidas a ustedes que me han demostrado afecto, me han impulsado a seguir con mi labor y también me han dado ánimos en momentos de desfallecimiento que son inevitables» ${ }^{19}$. Y es que a su gran producción científica sabía añadir su dosis de sencillez y cercanía para quienes compartían sus tesis o simplemente estaban interesados en el trabajo psicoanalítico.

Trabajar en las instituciones estatales, y también en el sistema sanitario, resultaba difícil. A la obligatoriedad de la afiliación al Partido Peronista de todas las personas de la administración pública se sumó la hostilidad creciente en las cátedras universitarias y en el medio hospitalario desde sectores simpatizantes con el nacionalsocialismo hacia los sectores progresistas, gentes de izquierdas y judíos principalmente, que obligó al incipiente movimiento psicoanalítico porteño a refugiarse en la práctica privada. No es casual que, sólo en la Universidad de Buenos Aires, en 1946, fueran cesados 1250 profesores quedándose sólo los llamados «flor de ceibo», así llamados por su adhesión al peronismo.

Es notorio en su obra su deseo de ir más allá de lo que habían pensado «los maestros». La obra de un investigador de espíritu libre. Desde sus años de formación destacó por evitar el sometimiento a las teorías previas. Recordemos su trabajo para acceder a la asociación psicoanalítica alemana criticando algunos trabajos recientes de Freud sobre psicosis y neurosis. Como también fue crítico con Melanie Klein que, aunque reconoció sus grandes aportaciones y haberse apoyado en algunos de sus estudios en medicina psicosomática, llegó a rechazar cuando no estuvo de acuerdo. «Siempre crítico de modo creativo», decía. Siempre preocupado de la expansión del psicoanálisis. El psicoanálisis era su vida, siempre estaba presente. Vivía para el trabajo, y para disfrutarlo como padre, esposo o amigo había que atraerlo, buscar los huecos de la persona que aunque muy exigente también era extraordinariamente cálida.

Y qué decir de su preocupación por la lectura y por favorecer la capacitación de los demás. Intentó complementar la biblioteca de la APA en todo momento, con nuevas publicaciones y copias microfilmadas de aquellos escritos imposibles de 
obtener dotándole de un ambiente digno y un buen nivel de funcionamiento. Decía recordar un dicho de Ramón Gómez de la Serna: «Un libro es un ser sensible, cuando se presta, se siente maltratado y no vuelve donde su dueño» y él añadía: «creo que los libros deben ser prestados, pero vigilando su destino. Es lo que he hecho también con mi biblioteca particular. Nunca he negado un libro a nadie, pero siempre he apuntado dónde se encontraba ${ }^{20}$. Prestaba libros y conversaba sobre ellos compartiendo su entusiasmo por el conocimiento.

\section{9: Ángel Garma vuelve a Europa}

Con los viajes a Europa y a diversos lugares de Sudamérica en la década de los años cincuenta y sesenta acontece la época de madurez de Ángel Garma. Tras la segunda guerra mundial, Garma acompaña a Elizabeth Goode, con quien se casaría poco después, al primer Congreso de psicoanálisis de postguerra, el XVI Congreso Internacional, que se realizó en Zurich. Fue en 1949 y la asociación argentina, la APA, obtuvo la afiliación formal a la Internacional de Psicoanálisis. «Cuando fuimos a ese congreso, me di cuenta que el grupo europeo le valoraba y admiraba el trabajo que él había hecho. Por ejemplo, Paula Heimann que fue compañera de él de seminarios en el Instituto de Berlin a finales de los años veinte, y ella en esos momentos era la segunda y muy íntima de Melanie Klein. No se separaban ni un minuto», comentaba Betty. Allí entabló amistad con Lacan que en ese congreso volvió sobre «el estadio del espejo» como formador del Yo, atacando a Anna Freud y a partidarios de la psicología del Yo. Debaten, junto a Arnaldo y Matilde Rascovsky y Teodoro Schlossberg, con Anna Freud, Melanie Klein y otros destacados integrantes del grupo kleiniano como Paula Heimann, Betty Josephs, Hanna Segal, etc. Melanie Klein disfrutó muchísimo de una presentación clínica de Elisabeth Goode (Betty) sobre un niño de 21 meses (Pedrito), el analizado más joven hasta entonces, menor aún que la famosa Rita. Betty pionera en el psicoanálisis de niños en Latinoamérica a partir de las supervisiones de sus propios historiales, recibió la invitación de este grupo para permanecer un año en Londres, debido fundamentalmente a sus trabajos asombrosos para la época, en los que se pudieran comprobar hipótesis y teorías de Klein. Betty tuvo que declinar el ofrecimiento, y además la propuesta contó con el rechazo de Garma porque las dinámicas y prioridades eran otras. Ese viaje a Londres se concretó más tarde en los años 1951-52, junto con Ángel Garma, y durante ese tiempo concurrieron a semina- 
rios, reuniones de estudio y supervisiones diarias. Fue Melanie Klein quien, tras escuchar un trabajo de Garma en Londres le reprochó: «lo que pasa es que usted no es suficientemente kleiniano» a lo que Ángel contestó «no, porque yo soy garmiano».

\section{BIBLIOGRAFÍA}

(1) ARbiSER, S., «Psichoanalysis in Argentina», Journal of the American Psychoanalytic Association, Supl., 2003.

(2) Balán, J., Profesión e identidad en una sociedad dividida: la medicina y el origen del psicoanálisis en la Argentina, Buenos Aires, CEDES, 1988.

(3) BALÁN, J., Cuéntame tu vida. Una biografía colectiva del psicoanálisis argentino, Buenos Aires, Planeta Espejo de la Argentina, 1991.

(4) BernaRd, R., «Por qué Klein y por qué no Klein. Reflexiones sobre el desarrollo de las ideas psicoanalíticas en el Río de la Plata», Revista de Psicoanálisis, 2002, n. ${ }^{\circ} 2$.

(5) Bergman, G., Las psicoterapias y el psicoterapeuta, Buenos Aires, Paidós, 1964.

(6) CAMPOS, J., «Recuerdos, olvidos y reminiscencias o la SEPTG y «sus viejas historias». A un psiquiatra olvidado», 1995. El profesor Emilio Mira y López en www.septg.org/historia/ hist00.htm, www.bibliopsiquis.com/miraylopez/caleidoscopio.htm.

(7) Carles, F., y otros, Psicoanálisis en España (1893-1968), Madrid, AEN, 2000.

(8) Carles, F.; MuÑoz, I.; LloR, C., «El psicoanálisis en España en el siglo actual», en Angosto, T.; Rodríguez, A.; Simón, D. (compiladores), 1924-1999. Setenta y cinco años de historia de la psiquiatría, AEN, AGSM, 2001.

(9) Cesio, F., La Gesta Psicoanalítica en América Latina, Buenos Aires, La Peste, 2000.

(10) Cucurullo, A.; Faimberg, H.; Wender, L., «La Psychanalyse en Argentine», en Histoire de la Psychanalyse, bajo la dirección de Roland Jaccard, tomo II, París, Le Livre de Poche, Biblio essais, 1982.

(11) CUETo, E., Entrevista a Betty Garma, www.elsigma.com/entrevistas/

(12) EsPIRO, N., «Dr. Ángel Garma (1904-1993): Iniciador de la formación y el movimiento psicoanalítico en Argentina 2», Revista de la AEN, 1993, XIII, n. ${ }^{\circ} 44$, pp. 3-4.

(13) Etchegoyen, R.; Horacio y Zysman, S., Melanie Klein en Buenos Aires. Comienzos y desarrollos, Buenos Aires, 2004. www.apdeba.org/secretaria@apdeba.org y www.alhp.org/ foro20.htm

(14) Feldman, N., La psychiatrie en Argentine. Tendances et Évolution au XIX et au XXème siècle. Psychiatrie et Psychanalyse. Le Service de l'Hôpital de Lanus, París, Université René Descartes, 1992, V, Inter Región Île de France.

(15) Galende, E., Psicoanálisis y Salud mental, Buenos Aires, Paidós, 1999.

(16) García Arroyo, J. M., «Jacques Lacan: una biografía intelectual», An. Psiquiatría, 2004, Vol. 20, n. ${ }^{\circ}$ 10, pp. 439-445.

(17) GARCía REINOSO, D., «Psicología de alternativa: una herramienta de lucha», Territorios, 1986, n. ${ }^{\circ}$ 3, Buenos Aires, pp. 13-14.

(18) Garma, C., Betty por Betty Garma, Buenos Aires, Proa XXI, 2003. 1970.

(19) Garma, A., Nuevas aportaciones al psicoanálisis de los sueños, Buenos Aires, Paidós,

(20) Gillespie, R., Soldados de Perón. Los Montoneros, Buenos Aires, Grijalbo, 1998. 
(21) GLICK, T. F., «El impacto del psicoanálisis en la psiquiatría española de entreguerras», incluido en Ciencia y sociedad en España, editado por J. M. Sánchez Ron, Madrid, El Arquero, 1988.

(22) GonZÁlez Duro, E., Historia de la locura en España, Tomo III, Madrid, Temas de Hoy, 1996.

(23) HUERTAS, R., «Ciencia y mente sobre papel: sobre libros y bibliotecas psiquiátricas», en VV. AA., Ciencia y mente: la salud mental en los fondos bibliográficos asturianos, Oviedo, AEN, 2003.

(24) HUERTAS, R., Los médicos de la mente. De la neurología al psicoanálisis, Lafora-VallejoGarma, Madrid, Nivola, 2002.

(25) Jones, E., Freud, Barcelona, Salvat, 1984.

(26) Kaplan, A., «La emigración de los psicoanalistas de América del Sur», IX Encuentro Internacional de la Historia del Psicoanálisis, 2002, Barcelona.

(27) LANGER, M., «Psicoanálisis y política: vicisitudes del movimiento psicoanalítico argentino», Clínica y análisis grupal, 1976, n. ${ }^{\circ}$ 1, pp. 94-106.

(28) Langer, M.; Del Palacio, J.; Guinsberg, E., Memoria, historia y diálogo psicoanalítico, Buenos Aires, Folios, 1984.

(29) LÁZARO, J., «Archivos de Neurobiología: Los setenta y cinco años de psiquiatría española», en APARICIO, V. (compilador), Orígenes y fundamentos de la Psiquiatría en España, Madrid, ELA, 1997.

(30) Markez, I., El bilbaíno Ángel Garma: fundador del psicoanálisis argentino, Bilbao, Fundación BBK, 2005.

(31) MuÑoz, M. L., «Contribución a la historia del movimiento psicoanalítico en España», Revista de psicoanálisis, Madrid, 1989.

(32) NeIBURG, F., Los intelectuales y la invención del peronismo, Buenos Aires, Alianza, 1998.

(33) Pérez-Villanueva, I., La Residencia de Estudiantes. Grupos Universitarios y de Señoritas. Madrid, 1910-1936, Madrid, MEC, 1990.

(34) Plotkin, M. B., Freud en las Pampas. Orígenes y desarrollo de una cultura psicoanalítica en la Argentina (1910-1983), Buenos Aires, Sudamericana, 2003.

(35) Resnicoff, B., Breve reseña del desarrollo del Psicoanálisis en la Argentina (desde un punto de vista testimonial), 2001. http://www.alhp.org/foro12.htm

(36) RodríGUez PéReZ, J. F., «La significación de Ángel Garma en el psicoanálisis hispánico», en APARICIO, V. (compilador), Orígenes y Fundamentos de la Psiquiatría en España, Madrid, ELA, 1997.

(37) SÁEnz de la CalzadA, M., La Residencia de Estudiantes (1910-1936), Madrid, CSIC, 1986.

(38) SÁnchez-Medina, G., Sesenta años del Psicoanálisis en Latinoamérica. Ramón Sarró y Angel Garma, Documentos RNE 1, 26-7-2002.

(39) TeICHER, M., Marie Lisbeth Glas de Langer (Mimi Langer). Historias que hacen Historia, http://www.psiconet.com/tiempo/historias/langer.htm

(40) Tumas, D., «Un testimonio. Entrevista al Dr. Valentín Barenblit», en Diarios Clínicos, 1990, 2, pp. 112-119.

(41) VisaCovsky, S., El Lanús. Memoria y política en la construcción de una tradición psiquiátrica y psicoanalítica argentina, Buenos Aires, Alianza, 2002.

(42) Wender, L., Orígenes del Psicoanálisis y de su Institucionalización en la Argentina, Conferencia en el Círculo Eros, Grupo de estudios del Departamento de Historia del Psicoanálisis, 2001, Buenos Aires, 2001.

(43) ZAK DE GoldsteIN, R., «El pensamiento psicoanalítico pionero de Ángel Garma», Revista de Psicoanálisis, 1974, Vol. 31, n. ${ }^{\circ}$ 4, pp. 843-879. 